Provided for non-commercial research and education use. Not for reproduction, distribution or commercial use.

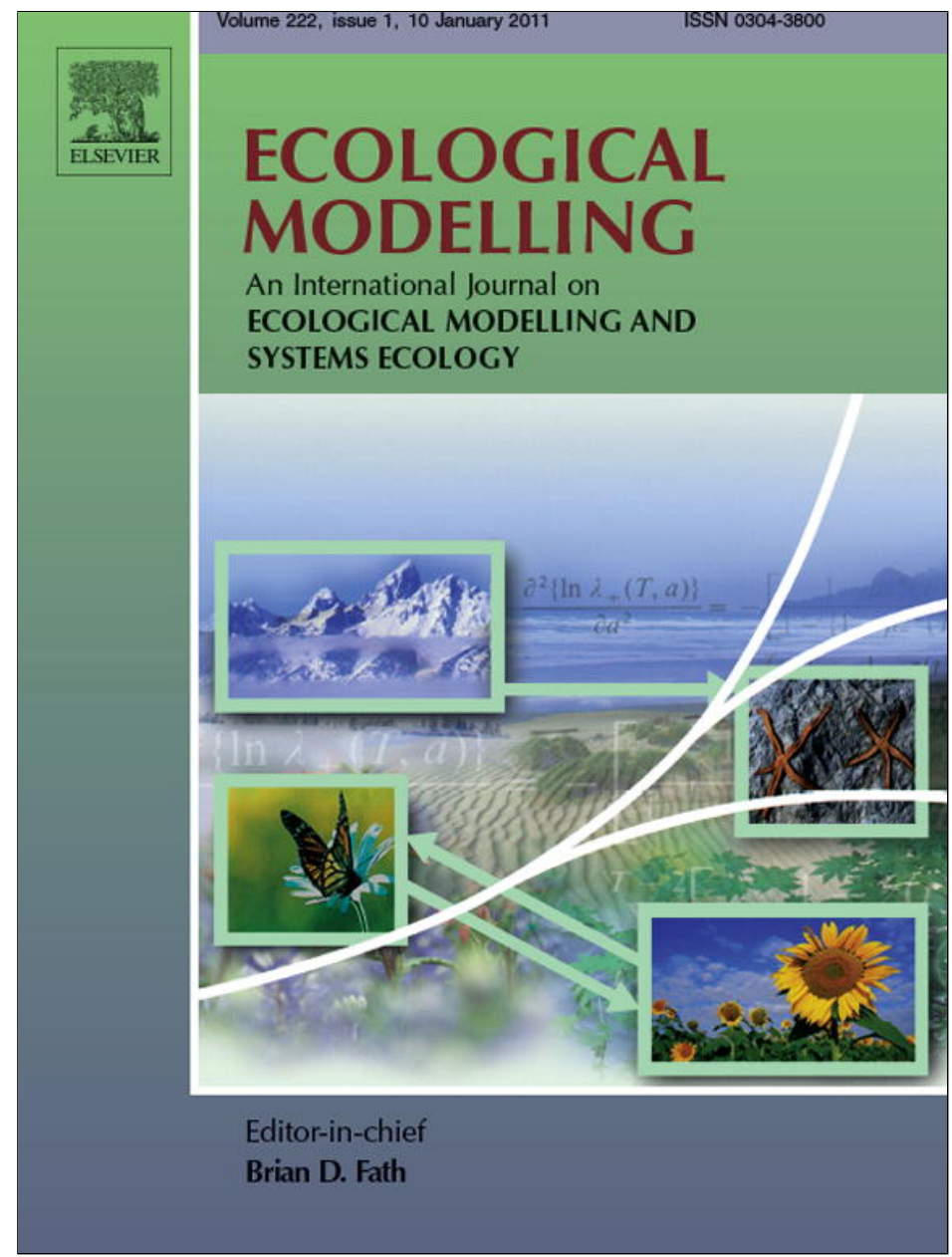

(This is a sample cover image for this issue. The actual cover is not yet available at this time.)

This article appeared in a journal published by Elsevier. The attached copy is furnished to the author for internal non-commercial research and education use, including for instruction at the authors institution and sharing with colleagues.

Other uses, including reproduction and distribution, or selling or licensing copies, or posting to personal, institutional or third party websites are prohibited.

In most cases authors are permitted to post their version of the article (e.g. in Word or Tex form) to their personal website or institutional repository. Authors requiring further information regarding Elsevier's archiving and manuscript policies are encouraged to visit:

http://www.elsevier.com/copyright 


\title{
Modelling the spatio-temporal pattern of primary dispersal in stone pine (Pinus pinea L.) stands in the Northern Plateau (Spain)
}

\author{
Rubén Manso $^{\mathrm{a}, *}$, Marta Pardos ${ }^{\mathrm{a}}$, Christopher R. Keyes ${ }^{\mathrm{b}}$, Rafael Calama ${ }^{\mathrm{a}}$ \\ a Dpto. Selvicultura y Gestión Forestal, CIFOR-INIA, Ctra. La Coruña km 7.5, 28040 Madrid, Spain \\ ${ }^{\mathrm{b}}$ Department of Forest Management, College of Forestry E' Conservation, University of Montana, Missoula, MT 59812, USA
}

\section{A R T I C L E I N F O}

\section{Article history:}

Received 19 April 2011

Received in revised form

21 November 2011

Accepted 25 November 2011

\section{Keywords:}

Inverse modelling

Fecundity

Crown effect

Seed limitation indexes

Climate control

Regeneration fellings

\begin{abstract}
A B S T R A C T
Natural regeneration in stone pine (Pinus pinea L.) managed forests in the Spanish Northern Plateau is not achieved successfully under current silviculture practices, constituting a main concern for forest managers. We modelled spatio-temporal features of primary dispersal to test whether (a) present low stand densities constrain natural regeneration success and (b) seed release is a climate-controlled process. The present study is based on data collected from a 6 years seed trap experiment considering different regeneration felling intensities. From a spatial perspective, we attempted alternate established kernels under different data distribution assumptions to fit a spatial model able to predict $P$. pinea seed rain. Due to $P$. pinea umbrella-like crown, models were adapted to account for crown effect through correction of distances between potential seed arrival locations and seed sources. In addition, individual tree fecundity was assessed independently from existing models, improving parameter estimation stability. Seed rain simulation enabled to calculate seed dispersal indexes for diverse silvicultural regeneration treatments. The selected spatial model of best fit (Weibull, Poisson assumption) predicted a highly clumped dispersal pattern that resulted in a proportion of gaps where no seed arrival is expected (dispersal limitation) between 0.25 and 0.30 for intermediate intensity regeneration fellings and over 0.50 for intense fellings. To describe the temporal pattern, the proportion of seeds released during monthly intervals was modelled as a function of climate variables - rainfall events - through a linear model that considered temporal autocorrelation, whereas cone opening took place over a temperature threshold. Our findings suggest the application of less intensive regeneration fellings, to be carried out after years of successful seedling establishment and, seasonally, subsequent to the main rainfall period (late fall). This schedule would avoid dispersal limitation and would allow for a complete seed release. These modifications in present silviculture practices would produce a more efficient seed shadow in managed stands.
\end{abstract}

(c) 2011 Elsevier B.V. All rights reserved.

\section{Introduction}

Pinus pinea is an essential species of Mediterranean ecosystems that provides important economic benefits to local population from its edible seed production and timber production. In addition, the species plays a valuable ecological role as its natural distribution occupies challenging sites that exhibit general Mediterranean weather conditions, continental winters and highly sandy soils, where few arboreal species persist. Such an environment can be often found throughout the Spanish Northern Plateau (Prada et al., 1997), which accounts for more than 50,000 ha of indigenous

\footnotetext{
* Corresponding author. Tel.: +34913471461; fax: +34913476767.

E-mail addresses: manso.ruben@inia.es, rmgforestal@hotmail.com

(R. Manso), pardos@inia.es (M. Pardos),christopher.keyes@cfc.umt.edu(C.R. Keyes),
} rcalama@inia.es (R. Calama).
$P$. pinea forests. These stands have been managed for over a century through modern silviculture techniques.

$P$. pinea natural regeneration has become a primary concern for forest management. Like other Mediterranean species (e.g. species of genus Quercus), natural regeneration is commonly unsuccessful under currently applied silvicultural systems (seed tree method, and, increasingly, shelterwood method), which lead to low densities to optimize cone production per tree. Regeneration fellings derived from these treatments produce even-aged non-coetaneous stands as they intend to imitate natural forest decay leading generally to these structures (Schütz, 2002). Several factors have been noted as determinants of this regeneration failure, including: climate, and specifically severe summer droughts and high summer temperatures that lead to establishment failure; masting habit and lack of synchrony with regeneration fellings and adequate years for seedling establishment; intensive cone harvesting, resulting in depauperate seed banks prior to regeneration felling; long rotations, inducing poor seed crops during the regeneration period due 
to tree vigour decline; the species' gravity-based seed dispersal strategy, resulting in patchy seed distribution; and post-dispersal seed predation (Calama and Montero, 2007; Barbeito et al., 2008; Manso et al., 2010).

The study of primary seed dispersal spatial patterns has focused on understanding the general mechanisms that control fundamental population dynamics (Clark et al., 1998, 1999b; Nathan et al., 2002; Levin et al., 2003; Muller-Landau et al., 2008; Martínez and González-Taboada, 2009), or their ecological consequences in local circumstances (Ordóñez et al., 2006; Santos et al., 2006; Debain et al., 2007; Gómez-Aparicio et al., 2007; Sagnard et al., 2007). Similarly, most studies about cone opening processes have mainly aimed to test the relative importance of pyriscence and xeriscence strategies from an ecological perspective (Nathan et al., 1999, 2000), evolutionary perspective (Tapias et al., 2001) and structural perspective (Nathan and Ne'eman, 2004). With few exceptions (such as Tsakaldimi et al. (2004) or Ganatsas and Thanasis (2010)), little effort has been undertaken to apply the valuable information generated from ecological studies to inform practices of promoting natural regeneration.

The density of seeds deposited in a particular location within a stand is a function of stand stocking and the spatial arrangement of trees (source), and of seed production and the capacity for seed dispersal over long distances (Clark et al., 1998). Provided that the latter is a serious constraint for colonization in $P$. pinea, due to the species' large wingless seed (Magini, 1955), a deeper knowledge of seed dispersal spatial traits can offer essential information with reference to the suitability of current densities in stands after seed fellings for natural regeneration. Low stockings promote a higher cone production per tree (Calama et al., 2008) but may result in a seed arrival limitation (dispersal limitation). On the other hand, dense stands largely favor an even distribution of seeds but may contribute to insufficient seed production (seed limitation). Optimal densities would lead to a compromise between both situations, with acceptable trade-offs in both seed production and seed dispersal. Because cone opening is related to physical variables (Dawson et al., 1997), accurate predictions of seed release rates based on climate variables would allow for optimized temporal regeneration felling schedules.

In the present study, an established methodology to analyze the spatial pattern of seed dispersal was used. The methodology, introduced by Ribbens et al. (1994) to study the spatial distribution of seedlings from seed source locations, utilizes inverse modelling procedures in order to estimate the summed seed shadow from data collected in a seed trap experiment. Although broadly applied (Clark et al., 1998, 1999b; Uriarte et al., 2005; Debain et al., 2007; Sagnard et al., 2007; Nanos et al., 2010), the approach is not without controversy, especially with regard to the experimental design (Clark et al., 1999a). Recently, comparisons carried out with seed dispersal kernels attained from genetic analysis demonstrated that trap location can dramatically bias parameter estimation (RobledoArnuncio and García, 2007). Furthermore, a more stable and reliable estimation is achieved if the fitting process is independent of the fecundity parameter. It has also been argued that other considerations, such as the bias introduced by immigrant seeds (i.e. from no mapped sources), should be taken into account (Jones and Muller-Landau, 2008). For $P$. pinea, however, the relatively short dispersal distance (Rodrigo et al., 2007) and the availability of existing models to independently estimate seed production (Calama et al., 2008) severely reduce parameterization stability problems, and immigrant seeds occurrence can be safely considered negligible. In addition, potential bias derived from trap location can be minimized with a sensible trap deployment in order to obtain a larger representation of critical (and more relevant) dispersal distances.
Alternative kernels estimated by inverse modelling have been recently proposed based on different assumptions that deal better with species specific dispersal features. Mechanistic approaches (Greene and Johnson, 1989; Stoyan and Wagner, 2001; Wright et al., 2008) were specifically developed to model wind dispersed species kernels. From a non-mechanistic perspective, different variants of the Weibull distribution have been assessed (Ribbens et al., 1994; Clark et al., 1998), while improvements on those methods were attained to manage its specific rigid behavior (Clark et al., 1999b; Bullock and Clarke, 2000). Eventually, other empirical approaches comprising genetic procedures have been developed to obtain more accurate predictions (González-Martínez et al., 2006; Robledo-Arnuncio and García, 2007). For our study, we tested and compared the performance of alternative models, sensu Debain et al. (2007), selected according to $P$. pinea specific dispersal syndrome, as a useful protocol to achieve the best fit and, consequently, a correct interpretation of the phenomena. Additionally, from simulations assessed through the model of best fit, we calculated and compared source abundance and dispersal limitation index values (Clark et al., 1998; Muller-Landau et al., 2002) under P. pinea's two most common regeneration felling systems and a control stand (i.e. prior fellings).

The main aims of the present work were to understand, model and predict the spatio-temporal patterns of the primary dispersal in $P$. pinea managed stands in the Spanish Northern Plateau. The purpose was to identify the likely bottlenecks occurring during the first step of the natural regeneration process. Our hypotheses were (a) that current stand densities at rotation age in managed $P$. pinea forests condition natural regeneration success, and (b) there exists a climate control on the temporal pattern of primary dispersal, similar to the phenomenon driving cone production (Mutke et al., 2005a; Calama et al., 2011). Our findings will serve as an essential tool for forest managers attempting to achieve satisfactory natural regeneration of $P$. pinea.

\section{Materials and methods}

\subsection{Study site}

The study site is located at $700 \mathrm{~m}$ a.s.l. in a representative $P$. pinea stand on the flat sandy soils of the Northern Plateau, Spain. The study was performed in a 120-year-old even-aged pure stand in Corbejón y Quemados public forest $\left(41^{\circ} 28^{\prime} \mathrm{N}, 4^{\circ} 43^{\prime} \mathrm{W}\right)$. Site location was selected and regeneration felling treatments designed to represent typical conditions in a mature managed forest, when restrictions on cone collection for commercial purposes are commonly imposed to allow for seed rain and regeneration. Regeneration fellings commenced during 2002-2003 following the highly intensive seed tree method (ST) and the more progressive shelterwood method (SW). Both systems have been broadly applied as regeneration treatments for the species. Pre-felling and post-felling stand densities are shown in Table 1. Climate is continental-Mediterranean. Mean monthly temperatures range from $4.0^{\circ} \mathrm{C}$ in January to $21.7^{\circ} \mathrm{C}$ in July. Mean annual precipitation is $435 \mathrm{~mm}$, with a period of summer drought (July-September mean precipitation of $66 \mathrm{~mm}$ ). Site index is $15-16 \mathrm{~m}$ at 100 years, characteristic of a II class quality (Calama et al., 2003). This index defines the quality of a stand as a function of its dominant height at a particular age. The considered dominant height criterion was the height of those trees whose diameter at breast height $(1.3 \mathrm{~m}$; " $d b h$ ") was included among the $20 \%$ of the thickest trees of the stand (Weise, 1880).

Our study is part of a broader project focused on the overall process of $P$. pinea natural regeneration in the Northern Plateau. 
Table 1

Summary of stand densities.

\begin{tabular}{|c|c|c|c|c|c|c|c|}
\hline Plot & Treatment & $N b / f^{f}\left(h^{-1}\right)$ & $N^{d}\left(h^{-1}\right)$ & $B A^{\mathrm{e}}\left(\mathrm{m}^{2} / \mathrm{ha}\right)$ & $D g^{\mathrm{f}}(\mathrm{cm})$ & $H^{\mathrm{g}}(\mathrm{m})$ & $F C C^{\mathrm{h}}(\%)$ \\
\hline 1 & $\mathrm{ST}^{\mathrm{a}}$ & 144 & 46 & 8.17 & 47.6 & 13.6 & 19 \\
\hline 2 & ST & 115 & 48 & 9.37 & 49.9 & 15.5 & 22 \\
\hline 3 & ST & 156 & 46 & 6.99 & 44.1 & 12.6 & 14 \\
\hline 4 & $\mathrm{SW}^{\mathrm{b}}$ & 192 & 73 & 10.82 & 43.4 & 14.1 & 31 \\
\hline 5 & SW & 233 & 75 & 9.70 & 40.6 & 12.9 & 30 \\
\hline 6 & SW & 169 & 75 & 12.26 & 45.6 & 15.8 & 34 \\
\hline 7 & Control & 149 & 149 & 18.42 & 40.1 & 13.8 & 70 \\
\hline
\end{tabular}

a ST-seed tree method.

b SW-shelterwood method.

${ }^{c} \mathrm{Nb} / \mathrm{f}$-density prior fellings. After fellings.

d $N$-remaining density.

e BA-basal area.

${ }^{f}$ Dg-quadratic mean diameter.

g $H$-average height.

h FCC-forest canopy cover.

\subsection{Experimental design}

The primary dispersal trial was installed in 2005, to allow for a stand response to fellings in cone production. It consisted of six $60 \mathrm{~m} \times 80 \mathrm{~m}(0.48 \mathrm{ha})$ sample plots that were established under different stand densities produced by regeneration fellings. Densities in plots 1-3 were representative of the ST method, whereas those in plots 4-6 were distinctive of the SW method. On the one hand, these treatments provided a convenient range of stand densities, essential for modelling purposes. On the other hand, they offer an excellent framework for further model simulation. A $7.5 \mathrm{~m}$ buffer area was included around each plot, increasing the overall plot surface up to $0.7 \mathrm{ha}$. An available control plot (no fellings) of identical dimensions was used exclusively for simulation purposes. Graphic information about plots can be found in Fig. A.1 in Appendix A.

All trees within plots were stem mapped and measured. Tree measurements included $d b h$, total height, and 4 perpendicular crown radii in cardinal directions.

In May 2005, a systematic grid $(17.7 \mathrm{~m} \times 17.7 \mathrm{~m})$ of ten circular seed traps of $0.25 \mathrm{~m}^{2}$ was established within each of the six plots (control excluded). Two traps in plot 1 were destroyed at the beginning of the experiment and were discarded from the analysis. The shortest distance from a trap to plot boundary was $12 \mathrm{~m}$. The trap design was a bag made of textile fine mesh stapled on three wooden sticks at $1 \mathrm{~m}$ above the ground (to prevent rodent predation). Trapped seeds were collected on 60 occasions from trap deployment to January 2011 at intervals averaging 34.6 days (range from 19 to 70, standard error 1.26), with longest intervals corresponding to low intensity seed rain months or difficult access to plots (winter).

\subsection{Modelling the spatial pattern}

\subsubsection{The inverse modelling approach}

In order to determine the spatial pattern of dispersal, an approach based on non-mechanistic models involving inverse modelling procedures was attempted (sensu Ribbens et al., 1994). With this type of model, the seed shadow is calculated as the product of two factors: the kernel and source fertility. The first factor, the kernel $\left(k_{i j}\right)$, represents the probability that a seed is primary dispersed to location $i$, given a source $j$ and travelling, isotropically, a distance $r_{i j}(\mathrm{~m})$. The kernel implies parameters to be estimated which control the shape of the curve as a function of distance. The second factor is the fertility of the source. In our approach, the model developed by Calama et al. (2008) is used to estimate average cone weight $\left(w c_{j}\right)$ during the studied period (2005-2010) for each individual tree $j$. Rather than estimate a parameter to obtain the number of seeds from the response variable of the aforementioned model, we used the model developed by Morales (2009) to predict the number of seeds per $\mathrm{kg}$ of cones $(P)$. $P$ was calculated considering a constant fraction of cone weight attributable to seeds (0.259) and assuming an average seed weight of $0.615 \mathrm{~g}$. Consequently, the value $N_{i j}$ (seeds $/ \mathrm{m}^{2}$ ) of the generic seed shadow for a single tree $j$ at a location $i$ is defined as:

$N_{i j}=P \cdot w c_{j} \cdot k\left(r_{i j}\right)$

In the case of non-discrete sources (e.g. a stand), the number of seeds reaching a location $i$ is computed as the sum of the expected number of seeds dispersed to this location from the $T$ trees considered. In that case, the summed seed shadow can be expressed as:

$N_{i}=P \cdot \sum_{j=1}^{T} w c_{j} \cdot k\left(r_{i j}\right)$

Note that definition of the summed seed shadow leads to individual tree kernel parameterization.

\subsubsection{Source determination}

For modelling purposes, we optimized the number of sources $T$ to contribute to the summed seed shadow at a specific location. Therefore, we initially plotted the inverse cumulative rate of seed arrival to each trap along normalized distances (total distance between a trap $i$ and a tree $j(d c) /$ crown radius dimension $(d b)$ ) to the nearest tree. Crown radii were calculated as the distance from the crown centroid $j$ to dripline in the direction of the trap $i$ (Fig. 1). Such simplification indicates both the degree of clumping of data and the relative distance of traps no receiving seeds to the closest tree. The latter defines the maximum relative dispersal distance found from the data available ( 2 crown radii). Thus, the procedure to optimize the $T$ contributor seed sources was to exclude from analysis trees located over a distance of 2 crown radii from traps.

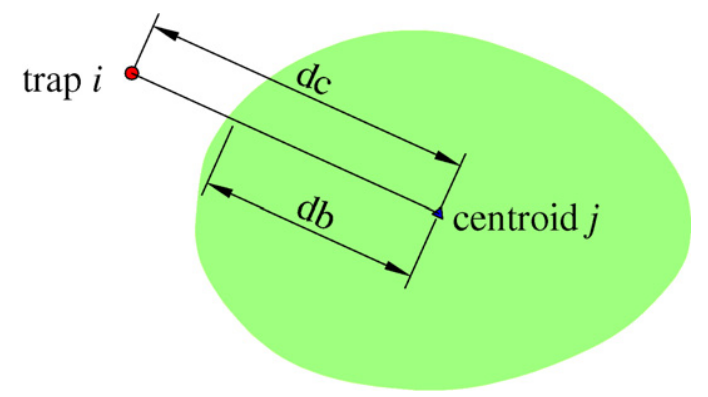

Fig. 1. Crown radii definition. $d b$ is the crown radius of tree $j$ and $d c$ the distance between centroid $j$ and trap $i$. 

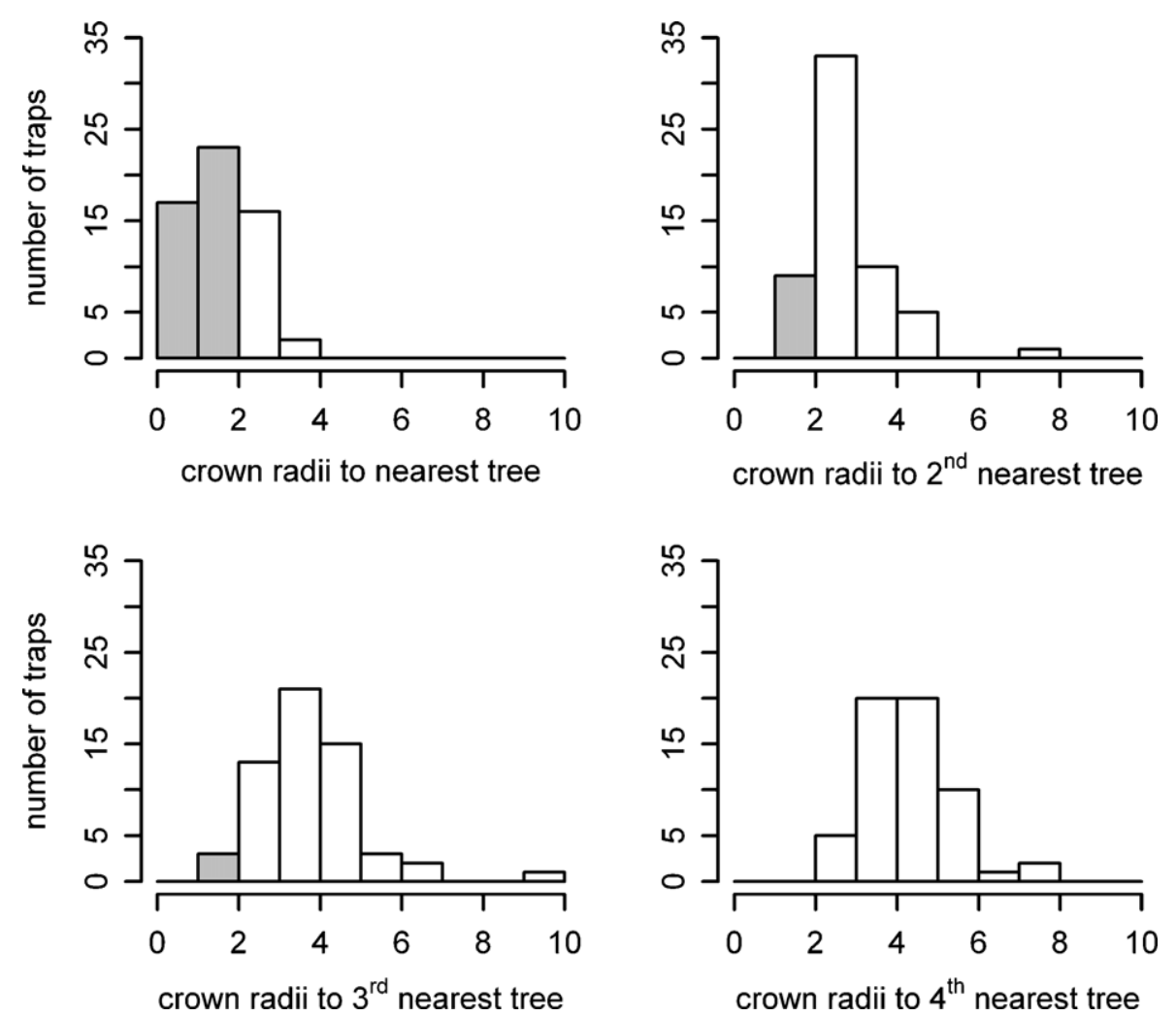

Fig. 2. Histograms of frequency for relative distances from trap $i$ to the closest 1 st, 2 nd, 3 rd and 4 th tree $j$. Distances below 2 crown radii are grey coloured for clarity. Note that the 4 th nearest tree was always further than 2 crown radii. Mean crown radius was $3.5 \mathrm{~m}$.

To do it, we calculated the empirical distribution of distances in crown radii from each trap to the stem of the nearest 1 st to $T$ th tree. Then, $T$ was considered optimum when the distribution of distances between traps and the $T$ th +1 nearest tree only included figures over 2 crown radii, resulting in $T=3$ (Fig. 2 ).

\subsubsection{Distance definition}

In order to account for crown effect in the kernel value assignment, we computed standardized distances between traps and sources, normalizing the beneath-crown segment $d b$ to an average crown radius $(\bar{R})$, leaving the rest (beyond crown) unaltered. When a trap was located beneath a crown shadow, its distance to source was assessed as the corresponding proportion of $\bar{R}$. In turn, beneath-crown distances are slightly rescaled, whereas two points located at the same distance to dripline of equally productive trees of different crown sizes are considered to be reached by the same number of seeds. Corrected distance $r_{i j}^{\prime}(\mathrm{m})$ analytic definition is then:

$(d c-d b)+\bar{R} \quad\{$ if the trap is beyond crown

$(d c / d b) \cdot \bar{R} \quad\{$ if the trap is beneath crown

where $d b$ is the real crown radius length; $d c$ is the distance between the centroid of tree $j$ and the trap $i$.

\subsubsection{Kernel formulation}

In order to estimate the seed shadow that best fit the data, two kernels were tested: the Weibull (Clark et al., 1998), and the 2Dt model (Clark et al., 1999b). Parameter estimation was performed through the optimization of the log-likelihood function for the assumed theoretical distribution of data, through a variant of the simulated annealing algorithm (Belisle, 1992).
The Weibull kernel can be re-formulated as:

$k_{i j}=\frac{1}{n} \exp \left[-\left(\frac{r_{i j}^{\prime}}{\alpha}\right)^{c}\right]$

where $\alpha$ is the dispersal parameter, $c$ is the shape parameter, $n$ is the normalizer:

$n=\frac{2 \cdot \pi \cdot \alpha^{2} \cdot \Gamma(2 / c)}{c}$

with $\Gamma(\cdot)$, the gamma distribution.

Shape parameter $c$ is assessed together with $\alpha$ in the $\log$ likelihood maximization. Nevertheless, whenever optimization becomes unstable we assumed, like Clark et al. (1998), a Gaussian curve $(c=2)$.

On the other hand, the 2Dt kernel consists of a reformulation of the Weibull curve with $c=2$, allowing $\alpha$ to vary along $r_{i j}$ :

$k_{i j}=\frac{u}{\pi \cdot p \cdot\left(1+\left(r_{i j}^{\prime 2} / p\right)\right)^{(u+1)}}$

where $u$ is the scale parameter, $p$ is the shape parameter.

\subsubsection{Likelihood functions}

Parameters involved in both $k_{i j}$ formulations were achieved through log-likelihood maximization of Eq. (2), under two alternative hypotheses (Poisson and negative binomial) with respect to the stochastic process of seed arrival. In the case of the 2Dt model, only the Poisson hypothesis was used. Poisson and negative binomial log-likelihoods adapted by Ribbens et al. (1994) and Clark et al. (1998), respectively, are expressed as:

$\log \ell=\sum_{i}\left(y_{i} \cdot \log N_{i}-N_{i}-\log y_{i} !\right)$ 


$$
\begin{aligned}
& \log \ell=\sum_{i}\left(\log \Gamma\left(y_{i}+\theta\right)-\log \Gamma\left(y_{i}+1\right)-\log \Gamma(\theta)+y_{i} \cdot \log N_{i}\right. \\
& \left.+\theta \cdot \log \theta-\left(y_{i}-\theta\right) \cdot \log \left(N_{i}+\theta\right)\right)
\end{aligned}
$$

where $\ell$ is the likelihood function to maximize, $y_{i}$ is the observed number of seeds collected from the trap $i, N_{i}$ is the expected number of seeds in trap $i, \theta$ is the clumping parameter, $\Gamma(\cdot)$ is the gamma distribution. Maximization of the log-likelihood functions was assessed using the data from all traps simultaneously.

\subsubsection{Model evaluation}

Comparisons between models were performed through the Akaike Information Criterion (AIC) to test model accuracy and select that one which best fitted the data. We also computed a regression between observed and expected seed density values, testing whether the intercept and slope differed significantly from 0 and 1 , respectively $\left(H_{0}\right.$ : intercept $=0$, slope $\left.=1\right)$, as a measure of the level of concordance between data and model. In addition, the coefficient of determination for this regression was calculated, as suggested by Clark et al. (1998).

\subsubsection{Seed limitation}

For the two proposed regeneration felling treatments and control, we tested whether changes in density (post-harvesting basal area) could lead to severe variations in seed availability (in regard to both abundance and occurrence). This was accomplished by computing the source limitation index, or $S L$, and the dispersal limitation index, or DL (Clark et al., 1998; Muller-Landau et al., 2002). $S L$ is expressed as the proportion of sites where no seeds arrive assuming that the total amount of seeds is distributed uniformly:

$S L=1-\operatorname{Pr}\left\{\hat{N}_{i}>0 \mid\right.$ Poisson $\left.\left(\sum \hat{N}_{i / l}\right)\right\}=\mathrm{e}^{-}\left(\sum \hat{N}_{i / l}\right)$

with $\hat{N}_{i}$, the expected number of seeds reaching the location $i$, and $l$, the number of locations taken into consideration. $D L$ can be defined as the comparison between the proportion of sites actually reached by dispersed seeds and the proportion of locations where seeds would arrive if dispersal were uniform, where $a$ is the number of points reached by at least one seed:

$D L=1-\left\{\frac{a / l}{1-S L}\right\}$

Using the best model, we assessed a simulated seed rain at $1 \mathrm{~m}^{2}$ scale throughout 2501 points $(l)$ located in a regular grid in the central $41 \mathrm{~m} \times 61 \mathrm{~m}$ rectangle of each plot. Regarding model consistence, distances between simulation points and trees must be modified similarly to Eq. (2). These simulations allowed for $S L$ and DL calculation throughout all plots, including the control.

\subsection{Modelling the temporal pattern}

In order to model seed dispersal from a temporal perspective, the total seed collected in traps during each data collection interval was graphically compared with that period's mean climate variables, including mean temperature, maximum temperature, mean relative humidity and total precipitation. Based on this analysis, the most suitable variables were selected to control the process of cone opening. All climate data were achieved from Olmedo meteorological station (coordinates $41^{\circ} 17^{\prime} 34^{\prime \prime} \mathrm{N}, 4^{\circ} 40^{\prime} 58^{\prime \prime} \mathrm{W}$ ).

Concerning seed release, we constructed a response variable $(s r)$ related to the total amount of collected seeds that also accounted for the seasonally decreasing aerial seed bank over time, as the percentage of seeds released in a particular period with respect to the total amount of seeds remaining in the cone. The nature of the response variable (a percentage) renders it insensitive to extremely low cone crops, thus we only considered years of appreciable crops in the analysis (i.e. 2006-2007, 2007-2008, 2008-2009 and 2010-2011). Significant differences among yields were determined via the non-parametric Kruskal-Wallis test for non-normal data $(\alpha=0.05)$.

A graphical analysis was also undertaken to identify prior relationships between climate variables and $s r$ as a basis to model $s r$ through a simple linear regression. In order to prevent unrealistic confidence intervals for the parameters, an auto-regressive error structure was applied within dispersal periods, due to the fact that the observations of the response variable are intrinsically autocorrelated from a temporal perspective. In addition, those cases where $s r=100$ were not used in the regression as it is a constant throughout all terminal values of every dispersal period with no ecological meaning. Eventually, potential transformations in explanatory variables were carried out when necessary to linearize the relationship. Model evaluation was performed comparing the AIC of alternative models.

All statistical analyses and calculations in this study were performed in R 2.12.0 (R Development Core Team, 2009).

\section{Results}

\subsection{Seed rain}

During the dispersal periods from 2005 to 2010, 753 seeds were collected in the seed plots. The spatial distribution of trapped seeds was not uniform. 24 traps (41\%) were not reached by any seed during all periods. The Kruskal-Wallis test indicated significant differences among years in number of seeds collected $\left(\chi^{2}=48.6924, p\right.$-value $\left.<0.0001\right)$. Dispersal was especially scarce (non-appreciable) during 2005-2006 (6 seeds) and 2009-2010 (7 seeds); higher yields occurred during 2008-2009 (29 seeds) and 2010-2011 (73 seeds). In contrast, 2006-2007 (237 seeds) and 2007-2008 (401 seeds) were strong masting years. Statistics per trap are summarized in Table 2.

Cone opening took place during June and July all years, when seeds reaching traps increased considerably. Concerning the progressive seed release after opening, although a strong dispersal peak occurred at the beginning of each dispersal period, a relative maximum at advanced stages of the process arose as a common feature for all years holding appreciable yields (Fig. 3). Notably, in 2006 a large portion of the year's dispersed seeds fell during November. The same trend occurred in 2007, when a high percentage of the year's seedfall was collected during September. In 2008, the peak occurred in October, while in 2010 two late maxima were recorded in September and November. During the years of appreciable cone crop, those data collection intervals of lesser seed rain intensity showed a residual (non-null) dispersal rate, with only four lags where no trapped seeds were found.

\subsection{Spatial pattern}

The Weibull model considering a Poisson distribution of data (henceforth W.P) proved the most accurate, with the lowest AIC value, together with the 2Dt model (Table 3 ). The maximization of the negative binomial log-likelihood function for the Weibull curve (hereafter W.NB) presented high instability in parameter estimation even fixing $c$. The clumping parameter in the negative binomial had a trend to large values $(\theta>100)$, meaning lack of overdispersion in the data.

Consistently, few differences in regard to prediction were found among all tested models. Even for the W.NB, which showed unstable parameter estimation, the range of attained parameters commonly tended to produce similar curves to those from the other 
Table 2

Main annual seed dispersal statistics per trap and seed rain density (seeds/ha).

\begin{tabular}{|c|c|c|c|c|c|c|}
\hline Period & 2005-2006 & 2006-2007 & 2007-2008 & 2008-2009 & 2009-2010 & 2010-2011 \\
\hline Mean & 0.10 & 4.09 & 6.91 & 0.50 & 0.12 & 1.26 \\
\hline $\mathrm{SD}^{\mathrm{a}}$ & 0.36 & 9.24 & 11.65 & 1.23 & 0.46 & 2.57 \\
\hline $\mathrm{CI}^{\mathrm{b}}(95 \%)$ & \pm 0.09 & \pm 2.38 & \pm 3.00 & \pm 0.32 & \pm 0.12 & \pm 0.66 \\
\hline Seeds/ha & 4137.93 & 163448.28 & 276551.72 & 20000.00 & 4827.59 & 50344.83 \\
\hline
\end{tabular}

SD: standard deviation.

b CI: confident intervals.

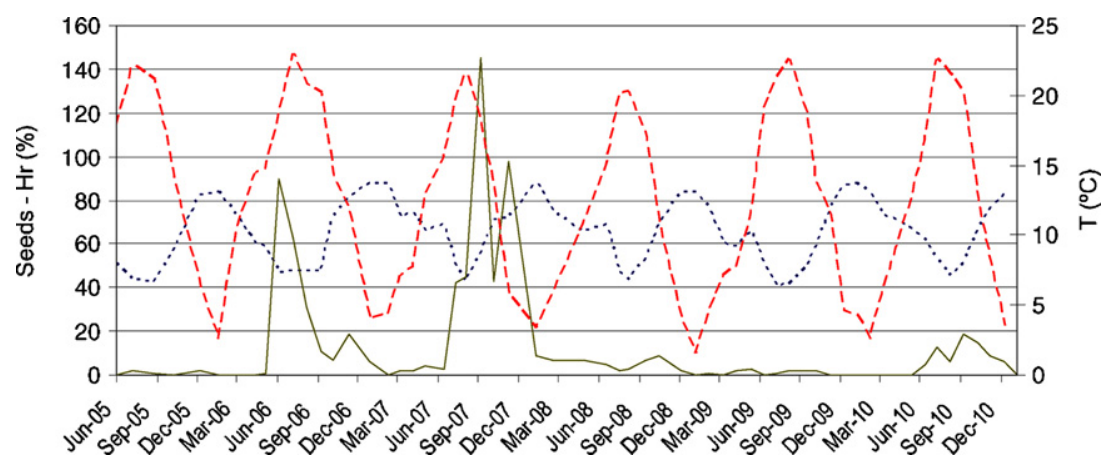

Fig. 3. Number of seeds trapped (solid line), monthly mean relative humidity (dotted line) and monthly mean temperature (dashed line) during $2005-2010$.

Table 3

Estimated parameters, AIC and $\log$-likelihood $(\log \ell)$ for the fitted models. In bolds, the lowest AIC. Coefficient of determination $\left(r^{2}\right)$ among observed and predicted values for each model is also shown.

\begin{tabular}{|c|c|c|c|c|c|c|c|}
\hline & $\alpha$ & c & $u$ & $p$ & AIC & $r^{2}$ & $\log \ell$ \\
\hline W.P & 3.308 & 2.065 & - & - & 2358.300 & 0.428 & -1177.150 \\
\hline $2 \mathrm{Dt}$ & - & $2^{a}$ & 24.837 & 253.6 & 2358.758 & 0.424 & -1117.379 \\
\hline
\end{tabular}

a Fixed parameter.

proposed approaches. Basically, the models differed in seed dispersal estimation at short distances (beneath crown) with expected density at source ranging from 39.89 (2Dt) to 37.71 seeds $/ \mathrm{m}^{2}$ (W.P), as illustrated in Fig. 4 for an average tree with a $3.5 \mathrm{~m}$ crown radius. The probability that a seed is dispersed beyond crown varied from 0.312 (W.P) to 0.310 (2Dt). Beyond $3.5 \mathrm{~m}$ from the dripline ( 2 mean crown radii), the probability was less than 0.01 for all models, indicating a highly aggregated spatial pattern (Fig. 5).

A high level of agreement between model and data was found in the case of the W.P model. As shown in Fig. 6 and Table 3, there were

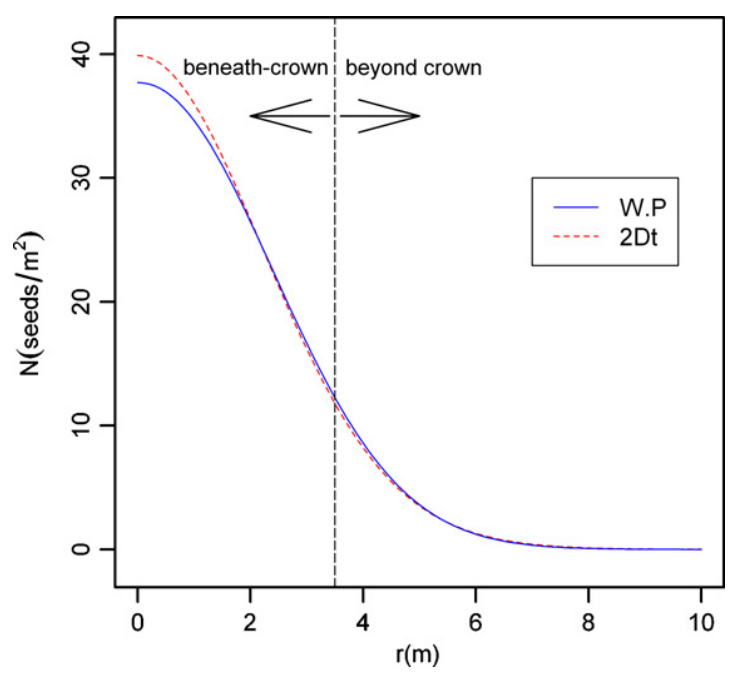

Fig. 4. Comparison of seed density curves produced by the fitted models for an average tree with crown radius $\bar{R}$. no evidences for rejecting the null hypothesis of a linear relationship with slope $=1(p$-value $>0.05)$ and intercept $=0(p$-value $=0.24)$ among observed and expected values. Coefficients of determination between them in the W.P and 2Dt models were similar (Table 3), exhibiting relatively low values.

Simulations to calculate limitation indexes were performed with the W.P model (Fig. 4). Source limitation index (Fig. 7) indicated that limitation due to seed availability was negligible for all plots $(S L<0.005)$, implying that under a uniform seed rain, most of the space would be reached. Dispersal limitation showed a tendency for lower values as basal area increased (Fig. 6). At low densities (basal area $<9 \mathrm{~m}^{2} /$ ha; plots 3 and 1 ), DL was 0.58 and 0.49 , respectively; it was 0.32 (plot 5), 0.29 (plot 2), 0.28 (plot 4) and 0.25 (plot 6), where basal area was between 9 and $13 \mathrm{~m}^{2} / \mathrm{ha}$. $D L$ in the control plot was 0.13 (basal area $=18.4 \mathrm{~m}^{2} / \mathrm{ha}$ ).

\subsection{Temporal pattern}

An exploratory analysis of different climate variables showed that cone opened when mean temperature of data collection intervals (mostly monthly) reached $19-20^{\circ} \mathrm{C}$ (Fig. 3). However, when considering the subsequent seed release, there was no apparent relationship of the number of harvested seeds to temperature variables or mean relative humidity.

On the contrary, when taking into account the percentage of seeds fallen during the collecting interval related to the overall amount of seeds to be released at the end of the dispersal period (sr), a synchronic pattern with total precipitation was found (Fig. 8; anomalous values in this trend were those corresponding to February and March of 2007).

The best fit at modelling $s r$ was achieved using the cubic root of total precipitation $(\sqrt[3]{p p})$ during the collection interval 


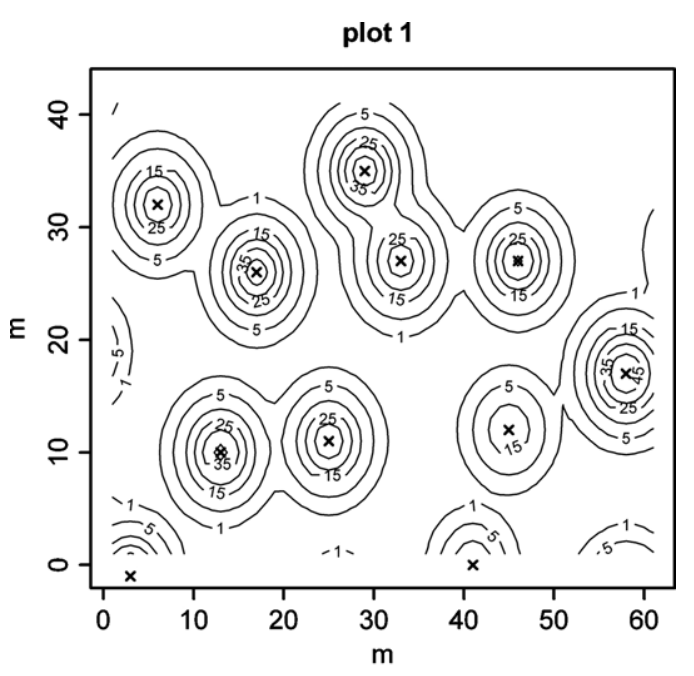

plot 4

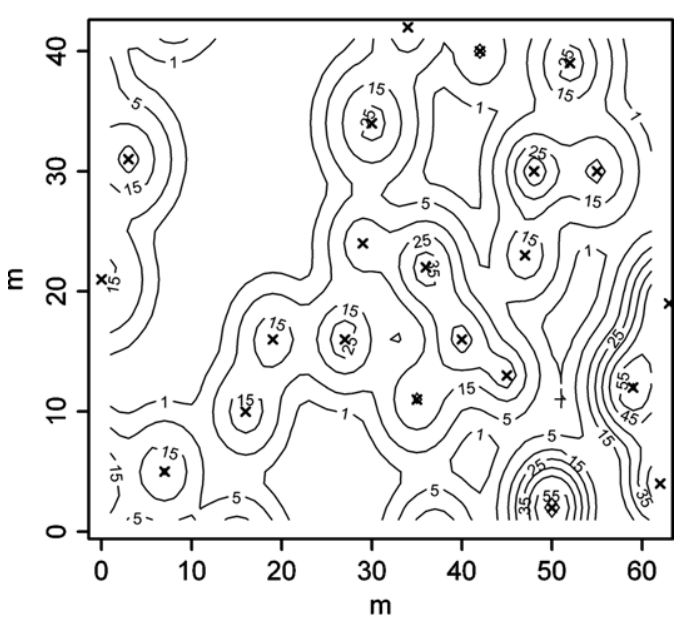

plot 7

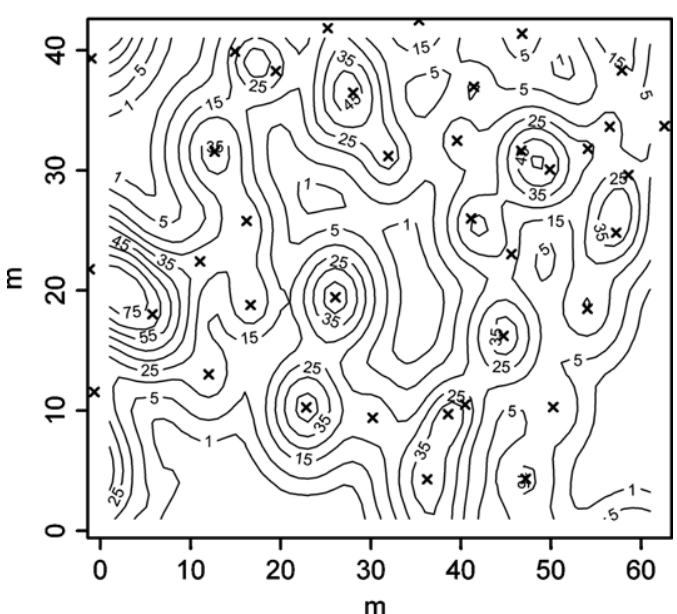

Fig. 5. Examples of seed shadow maps for plot 1 (ST treatment), plot 4 (SW treatment) and plot 7 (control). Crosses correspond to stems locations. Lines represent levels of equal predicted seed density (value indicated by the figure within lines).

as the explanatory variable (see Table 4, Fig. 9). A slight improvement in the AIC value was obtained when an autoregressive structure (AR-1) was applied within each dispersal period (ranging from 285.939 without structure to 284.538 with structure).

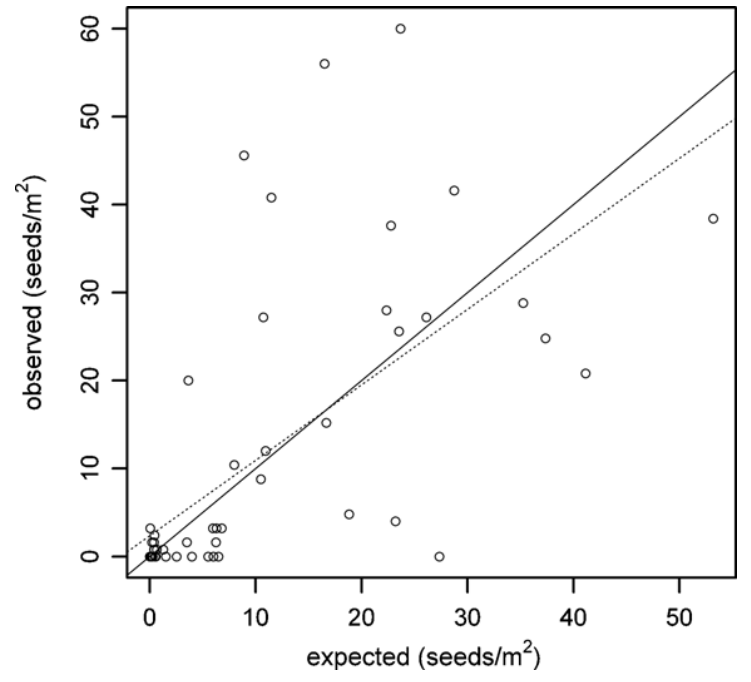

Fig. 6. Observed $v$ s expected seed shadow in traps $i$. Solid line indicates a theoretical perfect agreement between model and data (slope $=1$, intercept $=0$ ). Dotted line shows the real degree of accordance $($ slope $=0.858$; intercept $=2.361$ ).

\section{Discussion}

\subsection{The inverse modelling approach}

We attempted to fit empirical models using inverse modelling procedures to describe and predict seed shadow and, by implication, the spatial pattern of primary seed dispersal and its consequences in natural regeneration in $P$. pinea. Our main concern was short dispersal distance, particularly, the scope of the crown. Therefore, we used two competing models (Weibull and 2Dt) that work properly at this scale. Even though the flexibility of the 2Dt kernel was developed to account for long distance events (Clark et al., 1999b), those models have been reported to underestimate long dispersal distances (Debain et al., 2007), in comparison with the mixture model proposed by Bullock and Clarke (2000). Similarly, mechanistic approaches were not taken into consideration, as they have been developed using physical variables specifically related to wind dispersal mechanisms (e.g. Greene and Johnson, 1989; Bullock and Clarke, 2000; Stoyan and Wagner, 2001; but see also Martínez and González-Taboada, 2009) or even to model secondary dispersal by animals (Greene et al., 2004).

A serious constraint of inverse modelling is that plot size and spatial distribution of seed traps may lead to underestimation of mean dispersal distance when leptokurtic dispersal takes place (Robledo-Arnuncio and García, 2007). However, this problem does not severely apply to this study, as an extremely high kurtosis is not expected in $P$. pinea, provided gravity primary dispersal strategy in the species. In addition, our regular grid maximizes the number of traps between one and two crown radii, where dropped seeds in traps commence to be uncommon (deficient sampling in those circumstances could result in an unreliable parameter estimation). An indirect consequence of dispersal feature is that the arrival of

Table 4

Summary of the estimated coefficients for the fitted model between variable $s r$ and the cubic root of $p p$ (precipitation). $\varphi$ is the auto-regressive parameter of order 1 indicating correlation between 2 consecutive observations.

\begin{tabular}{lllll}
\hline & Coefficient & Standard error & $t$ & $p$-value \\
\hline Intercept & -0.0989 & 9.2157 & -0.0107 & 0.9915 \\
$\sqrt[3]{p p}$ & 10.1624 & 2.7346 & 3.7162 & 0.0008 \\
$\varphi$ & 0.3727 & - & - & - \\
\hline
\end{tabular}



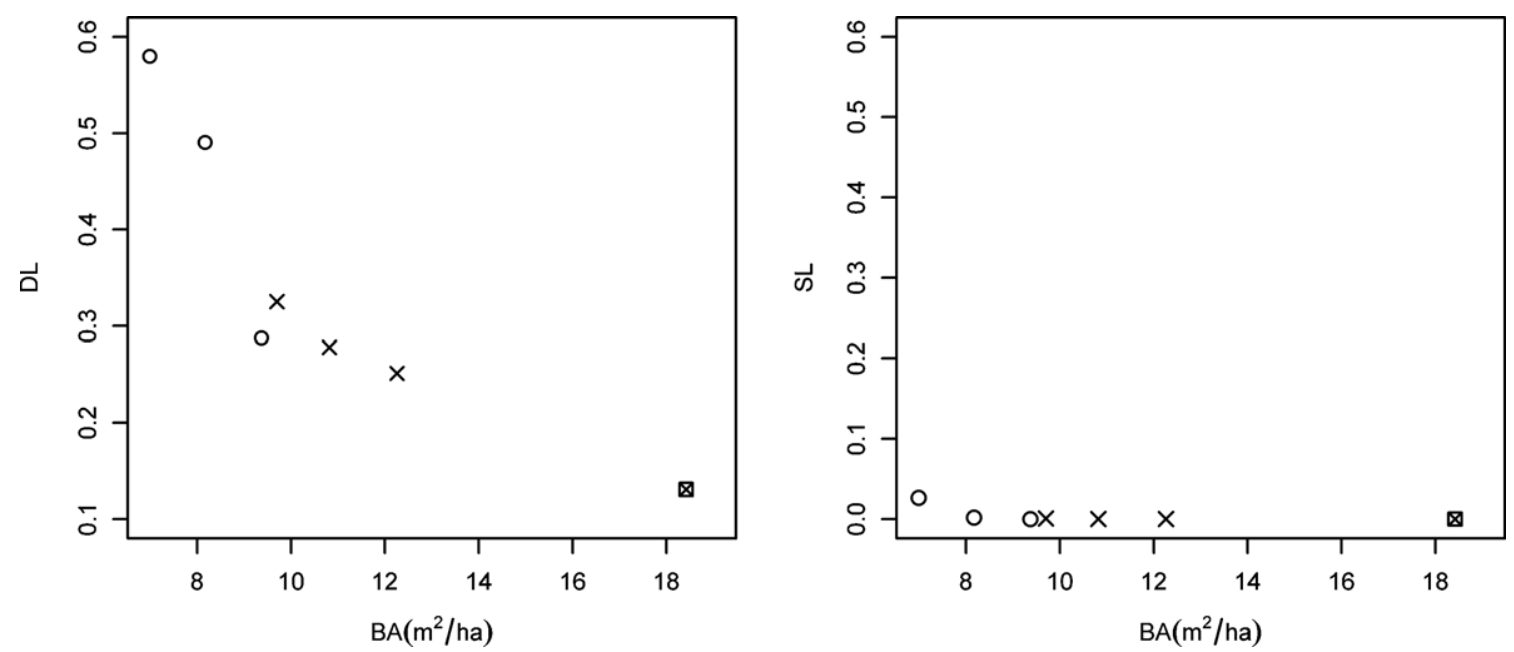

Fig. 7. Source limitation (SL) and dispersal limitation $(D L)$ indexes $v s$ BA ( $\mathrm{m}^{2} / \mathrm{ha}$ ) for the seven plots. Circles indicate seed tree treatment; crosses, shelterwood treatment; and the squared symbol corresponds to the control.

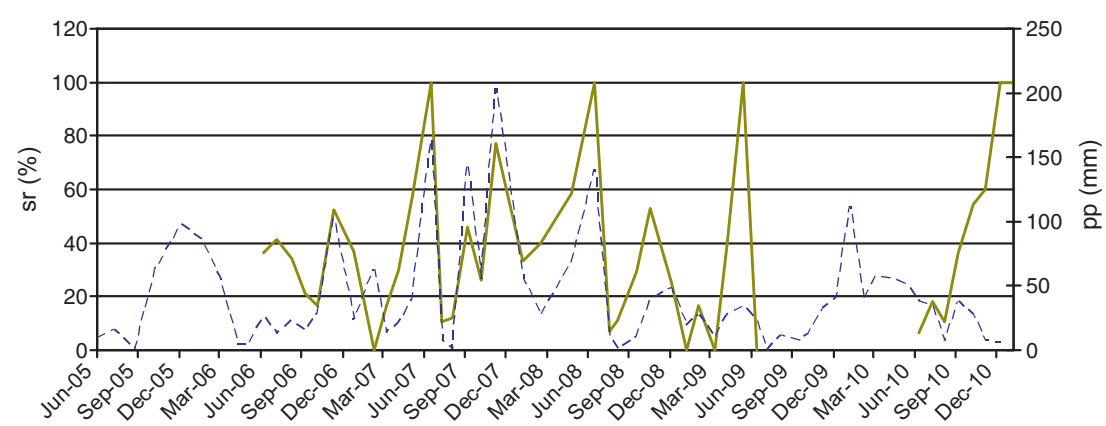

Fig. 8. Variable $\operatorname{sr}$ (solid line) and total precipitation per dispersal period (dashed line) in time. For clarity, we do not show $s r$ data from 2005 to 2006 and 2009 to 2010 dispersal periods (negligible). Note that $s r=100$ corresponds to the last value of each dispersal period.

immigrant seeds is expected to be a highly unlikely event in this case, considering also the spatial disposition of the grid in regard to the plot boundaries.

On the other hand, although genetic analysis deals with these difficulties, dispersal kernel estimation through parentage analysis requires the use of highly variable molecular markers, which

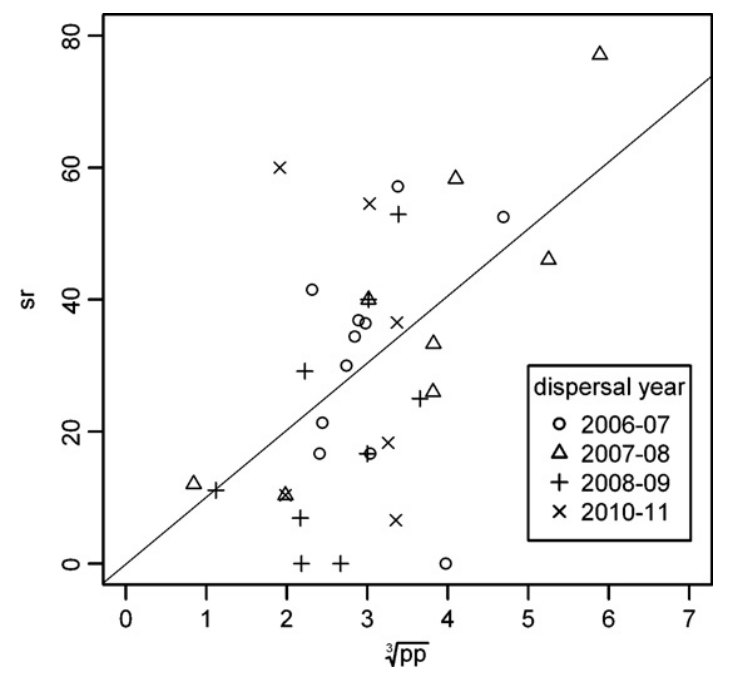

Fig. 9. Regression model for the temporal pattern of seed release (solid line) between $s r$ and the cubic root of total precipitation $(p p)$. Data from the dispersal years used to fit the model are displayed separately. provide an exact identification of all potential seed sources (Robledo-Arnuncio and García, 2007; Jones and Muller-Landau, 2008). This interesting and powerful technique is unfeasible to be applied in the case of $P$. pinea, due to the extremely low genetic diversity in the species (Vendramin et al., 2008).

Depending on the nature of the data, several authors have proposed different theoretical distributions to fit the dispersal models. The obvious approach is the Poisson distribution, as the response variable is obtained from counts (Ribbens et al., 1994; Sagnard et al., 2007). However, Clark et al. (1998) first appreciated the unsuitability of the Poisson process when clumping of data was present, suggesting the use of the negative binomial distribution instead. This interesting finding and the subsequent proposal may deal with clumping, at cost of an extra parameter $(\theta)$, being, in practice, a generalization of the Poisson approach. Indeed, $\theta$ tends to be large when data accommodates a Poisson process.

The 2Dt model involves the Poisson assumption by definition. This very flexible Gaussian model deals reasonably well with a clumped data distribution, not being essential to construct complex likelihood functions (Clark et al., 1999b). However, we attempted the negative binomial for the Weibull model. Parameter estimation became unstable and the clumping parameter frequently produced high figures $(\theta>100$; in contrast to Clark et al. (1998)). Consequently, we used the Poisson likelihood as a particular case of the negative binomial to achieve accurate estimates. Difficulties in fitting and lack of stability are not uncommon for poorly primary dispersed species (zoochorous and barochorus dispersal syndromes) as reported by Clark et al. (1998) and Martínez and González-Taboada (2009). 
Eventually, given the specific features of $P$. pinea spatial primary dispersal, all models showed a similar behavior in terms of prediction (comparable $r^{2}$ ), with slight differences nearby the stem. In addition, the coefficient of determination was relatively low, as a result of increasing variance with mean values (Poisson assumption), especially at short distances (below crown).

\subsection{Model improvements}

In accordance with the findings of Rodrigo et al. (2007), through our preliminary analysis to estimate the maximum relative dispersal distance (crown radii), it was observed that seed traps located further than two crown radii from the nearest tree seldom received any seed, dropping $80 \%$ of seeds under the crown. This circumstance, due to the aforementioned gravity dispersal pattern and to the low stand densities, allowed us to assume a limited number of sources associated with each trap. Consequently, it was possible to improve computing efficiency to assess high resolution distances and, in turn, to supply more accurate inputs for model fit. In addition, our systematic trap design, deployed throughout a variety of stand densities, provided a high range of distances under this assumption, which constitutes a desirable circumstance (Clark et al., 1998).

Commonly, inverse modelling procedures reduce seed sources to points. To our knowledge, there is no study where crown size has been taken into account in kernel parameterization, but Sagnard et al. (2007) in a different case study. Nevertheless, due to the umbrella-like shape of $P$. pinea crowns and cone occurrence throughout the upper fraction of the crown (Mutke et al., 2005b), the whole crown must be considered as a seed source. Besides, as its size may strongly influence primary seed arrival (Barbeito et al., 2008), it is of great interest to predict the proportion of seeds dropped beneath crowns. We propose a method that successfully accomplishes this objective. Providing that a summed seed shadow model impedes using relative distances (crown radii) between trees and traps, due to dimensional inconsistence, distances from trap to source are corrected, implying a double scale: beyond crown, distance to the dripline is known and unaltered, whereas beneath crown, relative distances are assessed in terms of crown radii ( 1 crown radius $=3.5 \mathrm{~m}$, mean crown radius at our experimental plots). Beyond its application in P. pinea stands, the approach provides an interesting tool to accurately study primary dispersal in large-seeded species with broad crowns (e.g. genus Quercus), with modest changes to customize the model (mean crown radius).

One of the main drawbacks in classic seed shadow estimation using inverse modelling is that it requires source fecundity figures. Frequently, these values are difficult to achieve and are defined as the product of some known variable related to seed productivity. For example, $d b h$ (Ribbens et al., 1994; Clark et al., 1998; Uriarte et al., 2005) or number of cones (Sagnard et al., 2007) plus a parameter to estimate number of seeds per $d b h$ unit or cone. A different approach was proposed by Nanos et al. (2010), where fecundity was allow to vary among trees without restrictions. The simultaneous estimation of fecundity and dispersal parameters may comprise high instability in the process (Clark et al., 2004; Nanos et al., 2010). In our approach, we reduced model complexity derived from this issue by estimating fecundity via the existing model developed by Calama et al. (2008) and the dimensional corrections assessed by Morales (2009), which enable accurate prediction of seed production in $P$. pinea as a function of $d b h$ and site index.

\subsection{Spatial pattern of seed dispersal}

The seed shadow estimated from the selected model (W.P) showed a highly aggregated spatial pattern of primary seed dispersal for $P$. pinea. Therefore, the presence of dropped seeds is bounded beneath crowns or in nearby areas (up to two crown radii for an average tree), in full accordance with the findings of Rodrigo et al. (2007). Simulations produced by the selected model allowed to attain source and dispersal limitation indexes. Comparisons of these indexes with the corresponding basal area values within each plot showed that source limitation was negligible for all plots considering the whole period, although due to the species' masting habit, limitation would occur frequently in no mast years (Calama et al., Unpublished data). Nevertheless, the results supported our hypothesis that current management densities are inefficient in regard to dispersal limitation. For post-harvest basal area values under both regeneration fellings (especially the seed tree method), the current seed shadows produced a notable percentage of gaps where dispersed seeds are not expected to arrive. These results are consistent with those from Dalling et al. (2002) when considering large-seeded, non-zoochorus species with low densities within a stand. This issue could limit natural regeneration if stand density is reduced prior to seedling establishment, particularly when basal area is reduced below a critical value of $10 \mathrm{~m}^{2} /$ ha (seed tree method). In that circumstance, the remaining trees are insufficient to successfully regenerate the stand, even if highly favorable dispersal events take place, and thus necessitating artificial regeneration (direct seeding). This scenario constitutes a common circumstance given current felling schedules, involving densities that range from 50 to 75 stems/ha during the first 10 years of the regeneration period (Montero et al., 2008).

\subsection{Temporal pattern of seed dispersal}

From a temporal perspective, the results also support our hypothesis that climate controls cone opening and seed release in $P$. pinea. During our study, cones opened in response to a temperature threshold $\left(19-20^{\circ} \mathrm{C}\right)$. Accordingly, Tapias et al. (2001), in a comparative study under controlled conditions, found that $P$. pinea cones opening took place as a punctual process at $28^{\circ} \mathrm{C}$ (the lowest temperature tested). On the other hand, the relationship between $s r$ and total precipitation could be connected to passive physical processes involving scale tissues structure and changes in relative humidity (Dawson et al., 1997). That would promote cone scales movements, alternatively opening and closing the cone, which would facilitate seed release. Contrastingly, Masetti and Mencussini (1991) observed dispersal peaks for $P$. pinea during the driest month in two correlative years in Toscana (Italy), although that analysis was performed without taking into account the seasonally declining of the canopy seed bank. In our case, such an effect was observed only during the dispersal peak that began in March 2007. A daily analysis of precipitation rates shows that most of the rainfall took place at the end of the previous interval (February) along correlative days. However, the dispersal peak was recorded next month (March, which was drier). This discrepancy might indicate that seed release can be controlled by alternate dry and humid events in climates characterized by a lower and more uneven precipitation than in Toscana, such as the Spanish Northern Plateau. Similarly, Nathan et al. (1999) claimed that Pinus halepensis seed release was strongly related to extremely dry and hot climate events. Although rainfall was not involved in the process, short changes in humidity with respect to prior daily values produced the release.

\subsection{Management implications}

Our findings suggest that under the current management of $P$. pinea stands in the Northern Plateau, primary dispersal could constitute a bottleneck for the species' natural regeneration, provided that secondary dispersal has not been documented and preliminary data confirm the absence of a secondary disperser for $P$. pinea in the area (Manso et al., in press). Interestingly, Pardos et al. (2010) found 
out poor physiological performance of seedlings located beyond the crown influence, whereas Calama et al. (Unpublished data) observed higher mortality in seedlings located beyond two crown radii from trees. In addition, Awada et al. (2003) established that $P$. pinea response to late shade releasing did not condition further plant development. Therefore, the absence of long dispersal distance events could apparently beneficiate the species. The models developed in this study showed a highly clumped dispersal spatial pattern, where the occurrence of seed rain is intimately related to rainfall events. Seed limitation indexes obtained from selected model simulations suggest that natural regeneration failure is due to, at least in part, dispersal limitation. In addition, as seed release proved climate-controlled, current felling schedules following no ecological criteria can result in unsuitable density reduction before dispersal takes place. These spatial and temporal constrictions limit dispersal through space and time, and indicate that present silviculture practices in P. pinea stands can be modified in order to optimize seed arrival. A reduction in the intensity of regeneration fellings and their scheduling a few years after the occurrence of favorable recruitment events would reduce the probability of regeneration failure through a more evenly distributed dispersal. Because the control dispersal limitation index showed a negligible seed limitation with respect to basal area, the residual densities at the beginning of the regeneration period should exceed $16-18 \mathrm{~m}^{2} /$ ha of basal area. Regeneration fellings should be limited to post-dispersal periods, after the rainfalls that follow cone opening in this area (i.e. October-December) in order to guarantee the release of all the seeds. In conclusion, silvicultural recommendations based on the models developed in the present study would increase the available seed in the soil bank necessary for the next processes in natural regeneration.

\section{Acknowledgements}

We are grateful to the Forest Service of the Junta de Castilla y León and in particular to Ayuntamiento de El Portillo for permission to conduct the field experiment. We also wish to thank Guillermo Madrigal and Enrique Garriga for their help in data collection. Finally, we would like to express our gratitude to David Affleck for his suggestions on R programming and Juan José Robledo-Arnuncio for his helpful comments that improved notably the text. This research was supported by INIA project RTA2007-00044.

\section{Appendix A. Supplementary data}

Supplementary data associated with this article can be found, in the online version, at doi:10.1016/j.ecolmodel.2011.11.028.

\section{References}

Awada, T., Radoglou, K., Fotelli, M.N., Constantinidou, H.I.A., 2003. Ecophysiology of seedlings of three Mediterranean pine species in contrasting light regimes. Tree Physiol. 23, 33-41.

Barbeito, I., Pardos, M., Calama, R., Cañellas, I., 2008. Effect of stand structure on stone pine (Pinus pinea L.) regeneration dynamics. Forestry 81, 617-629.

Belisle, C.J.P., 1992. Convergence theorems for a class of simulated annealing algorithms on R(d). J. Appl. Prob. 29, 885-895.

Bullock, J.M., Clarke, R.T., 2000. Long distance seed dispersal by wind: measuring and modelling the tail of the curve. Oecologia 124, 506-521.

Calama, R., Canadas, N., Montero, G., 2003. Inter-regional variability in site index models for even-aged stands of stone pine (Pinus pinea L.) in Spain. Ann. Fores Sci. 60, 259-269.

Calama, R., Gordo, F.J., Mutke, S., Montero, G., 2008. An empirical ecological-type model for predicting stone pine (Pinus pinea L.) cone production in the Northern Plateau (Spain). For. Ecol. Manage. 255, 660-673.

Calama, R., Manso, R., Barbeito, I., Madrigal, G., Garriga, E., Gordo, F.J., Montero, G., Cañellas, I., Pardos, M., Unpublished data. Does inter-specific differences in seed size determine natural regeneration traits in Pinus pinea and Pinus sylvestris?

Calama, R., Montero, G., 2007. Cone and seed production from stone pine (Pinus pinea L.) stands in Central Range (Spain). Eur. J. Forest Res. 126, 23-35.
Calama, R., Mutke, S., Tomé, J., Gordo, J., Montero, G., Tomé, M., 2011. Modelling spatial and temporal variability in a zero-inflated variable: the case of stone pine (Pinus pinea L.) cone production. Ecol. Model. 222, 606-618.

Clark, J.S., Beckage, B., Camill, P., Cleveland, B., HilleRisLambers, J., Lichter, J., McLachlan, J., Mohan, J., Wyckoff, P., 1999a. Interpreting recruitment limitation in forests. Am. J. Bot. 86, 1-16.

Clark, J.S., LaDeau, S., Ibanez, I., 2004. Fecundity of trees and the colonizationcompetition hypothesis. Ecol. Monogr. 74, 415-442.

Clark, J.S., Macklin, E., Wood, L., 1998. Stages and spatial scales of recruitment limitation in southern Appalachian forests. Ecol. Monogr. 68, 213-235.

Clark, J.S., Silman, M., Kern, R., Macklin, E., HilleRisLambers, J., 1999b. Seed dispersal near and far: patterns across temperate and tropical forests. Ecology 80 1475-1494.

Dalling, J.W., Muller-Landau, H.C., Wright, S.J., Hubbell, S.P., 2002. Role of dispersal in the recruitment limitation of neotropical pioneer species. J. Ecol., 90.

Dawson, J., Vincent, J.F.V., Rocca, A.M., 1997. How pine cones open. Nature 390, 668.

Debain, S., Chadoeuf, J., Curt, T., Kunstler, G., Lepart, J., 2007. Comparing effective dispersal in expanding population of Pinus sylvestris and Pinus nigra in calcareous grassland. Can. J. For. Res. 37, 705-718.

Ganatsas, P., Thanasis, G., 2010. Pinus halepensis invasion in Pinus pinea habitat in Strofylia forest (Site of NATURA 2000 network), southern Greece. J. Nat. Conserv. $18,106-117$.

Gómez-Aparicio, L., Gómez, J.M., Zamora, R., 2007. Spatiotemporal patterns of seed dispersal in a wind-dispersed Mediterranean tree (Acer opalus subsp granatense): implications for regeneration. Ecography 30, 13-22.

González-Martínez, S.C., Burczyk, J., Nathan, R., Nanos, N., Gil, L., Alía, R., 2006. Effective gene dispersal and female reproductive success in Mediterranean maritime pine (Pinus pinaster Aiton). Mol. Ecol. 15, 4577-4588.

Greene, D.F., Canham, C.D., Coates, K.D., Lepage, P.T., 2004. An evaluation of alternative dispersal functions for trees. J. Ecol. 92, 758-766.

Greene, D.F., Johnson, E.A., 1989. A model of wind dispersal of winged or plumed seeds. Ecology 70, 339-347.

Jones, F.A., Muller-Landau, H.C., 2008. Measuring long-distance seed dispersal in complex natural environments: an evaluation and integration of classical and genetic methods. J. Ecol. 96, 642-652.

Levin, S.A., Muller-Landau, H.C., Nathan, R., Chave, J., 2003. The ecology and evolution of seed dispersal: a theoretical perspective. Annu. Rev. Ecol. Evol. Syst. 34 575-604.

Magini, E., 1955. Sulle condizioni di germinazione del pino d'Aleppo e del pino domestico. Italia Forestale e Montana, Anno X:, 106-124.

Manso, R., Calama, R., Madrigal, G., Garriga, E., De Blas, S., Gordo, F.J., Pardos, M. Dispersión primaria, dispersión secundaria y predación post-dispersión en Pinus pinea L. In: J. Gordo, R. Calama, M. Pardos, F. Bravo and G. Montero (Eds.), La regeneración natural de Pinus pinea L. y Pinus pinaster Ait. en los arenales de la Meseta Castellana. Actas de las I Jornadas de Transferencia Tecnológica y Científica, in press.

Manso, R., Pardos, M., Garriga, E., De Blas, S., Madrigal, G., Calama, R., 2010. Modelling the spatial-temporal pattern of post-dispersal seed predation in stone pine (Pinus pinea L.) stands in the Northern Plateau (Spain). In: Frugivores and Seed Dispersal: Mechanisms and Consequences of a Key Interaction for Biodiversity, Montpellier, France.

Martínez, I., González-Taboada, F., 2009. Seed dispersal patterns in a temperate forest during a mast event: performance of alternative dispersal kernels. Oecologia 159, 389-400.

Masetti, C., Mencussini, M. 1991. Régénération naturelle du pin pignon (Pinus pinea L.) dans la Pineta Granducale di Alberese (Parco Naturalle della Maremma, Toscana, Italie). Ecol. Mediterr. 17, 103-188.

Montero, G., Calama, R., Ruiz Peinado, R., 2008. Selvicultura de Pinus pinea L. In: Montero, G., Serrada, R., Reque, J. (Eds.), Compendio de Selvicultura de Especies. INIA-Fundación Conde del Valle de Salazar, Madrid, pp. 431-470.

Morales, L., 2009. Modelos para la predicción del contenido y calidad de piñón en piñas de Pinus pinea L. en los valles del Tiétar y del Alberche. Master Thesis, Universidad Politécnica de Madrid, Madrid.

Muller-Landau, H.C., Wright, S.J., Calderon, O., Condit, R., Hubbell, S.P., 2008. Interspecific variation in primary seed dispersal in a tropical forest. J. Ecol. 96 653-667.

Muller-Landau, H.C., Wright, S.J., Calderón, O., Hubbell, S.P., Foster, R.B., 2002. Assessing recruitment limitation: concepts, methods and case-studies from a tropical forest. In: Levey, D.J., Silva, W.R., Galetti, M. (Eds.), Seed Dispersal and Frugivory: Ecology, Evolution and Conservation. CAB International, Wallingford, pp. 35-53.

Mutke, S., Gordo, J., Gil, L., 2005a. Variability of Mediterranean stone pine cone production: yield loss as response to climate change. Agric. Forest Metereol. 132 263-272.

Mutke, S., Sievanen, R., Nikinmaa, E., Perttunen, J., Gil, L., 2005b. Crown architecture of grafted stone pine (Pinus pinea L.): shoot growth and bud differentiation. Trees $19,15-25$.

Nanos, N., Larson, K., Milleron, M., Sjostedt-de Luna, S., 2010. Inverse modeling for effective dispersal: do we need tree size to estimate fecundity? Ecol. Model. 221 2415-2424.

Nathan, R., Katul, G.G., Horn, H.S., Thomas, S.M., Oren, R., Avissar, R., Pacala, S.W., Levin, S.A., 2002. Mechanisms of long-distance dispersal of seeds by wind. Nature 418, 409-413.

Nathan, R., Ne'eman, G., 2004. Spatiotemporal dynamics of recruitment in Aleppo pine (Pinus halepensis Miller). Plant Ecol. 171, 123-137. 
Nathan, R., Safriel, U.N., Noy-Meir, I., Schiller, G., 1999. Seed release without fire in Pinus halepensis, a Mediterranean serotinous wind-dispersed tree. J. Ecol. 87, 659-669.

Nathan, R., Safriel, U.N., Noy-Meir, I., Schiller, G., 2000. Spatiotemporal variation in seed dispersal and recruitment near and far from Pinus halepensis trees. Ecology $81,2156-2169$

Ordóñez, J.L., Molowny-Horas, R., Retana, J., 2006. A model of the recruitment of Pinus nigra from unburned edges after large wildfires. Ecol. Model. 197, 405-417.

Pardos, M., Puertolas, J., Madrigal, G., Garriga, E., de Blas, S., alama, R., 2010. Seasonal changes in the physiological activity of regeneration under a natural light gradient in a Pinus pinea regular stand. Forest Syst. 19, 367-380.

Prada, M.A., Gordo, J., De Miguel, J., Mutke, S., Catalán, G., Iglesias, S., Gil, L., 1997. Las regiones de procedencia de Pinus pinea L. en España. Ministerio de Medio Ambiente, Madrid.

Ribbens, E., Silander, J.A., Pacala, S.W., 1994. Seedling recruitment in forests-calibrating models to predict patterns of tree seedling dispersion. Ecology 75, 1794-1806.

Robledo-Arnuncio, J.J., García, C., 2007. Estimation of the seed dispersal kernel from exact identification of source plants. Mol. Ecol. 16, 5098-5109.

Rodrigo, A., Quintana, V., Retana, J., 2007. Fire reduces Pinus pinea distribution in the northeastern Iberian Peninsula. Ecoscience 14, 23-30.

Sagnard, F., Pichot, C., Dreyfus, P., Jordano, P., Fady, B., 2007. Modelling seed dispersal to predict seedling recruitment: recolonization dynamics in a plantation forest. Ecol. Model. 203, 464-474.

Santos, B.A., Melo, F.P.L., Tabarelli, M., 2006. Seed shadow, seedling recruitment, and spatial distribution of Buchenavia capitata (Combretaceae) in a fragment of the Brazilian Atlantic Forest. Braz. J. Biol. 66, 883-890.
Schütz, J.P., 2002. Silvicultural tools to develop irregular and diverse forest structures. Forestry 45, 329-337.

Stoyan, D., Wagner, S., 2001. Estimating the fruit dispersion of anemochorous forest trees. Ecol. Model. 145, 35-47.

Tapias, R., Gil, L., Fuentes-Utrilla, P., Pardos, J.A., 2001. Canopy seed banks in Mediterranean pines of southeastern Spain: a comparison between Pinus halepensis Mill., P. pinaster Ait., P. nigra Arn. and P. pinea L. J. Ecol. 89, 629-638.

R Development Core Team, 2009. R: A Language and Environment for Statistical Computing. R Foundation for Statistical Computing, Vienna, Austria.

Tsakaldimi, M.N., Tsitsoni, T.K., Zagas, T., Ganatsas, P.P., 2004. Aleppo pine (Pinus halepensis) natural regeneration, without fire, in the Kassandra Peninsula, northern Greece. In: Papanastasis, A. (Ed.), MEDECOS Conference. 25th April-1st May. Millpress, Rhodes, Greece.

Uriarte, M., Canham, C.D., Thompson, J., Zimmerman, J.K., Brokaw, N., 2005. Seedling recruitment in a hurricane-driven tropical forest: light limitation, density-dependence and the spatial distribution of parent trees. J. Ecol. 93, 291-304.

Vendramin, G.G., Fady, B., Gonzalez-Martinez, S.C., Hu, F.S., Scotti, I., Sebastiani, F. Soto, A., Petit, R.J., 2008. Genetically depauperate but widespread: the case of an emblematic mediterranean pine. Evolution 62, 680-688.

Weise, W., 1880. Ertragstafeln für Kiefer. J. Springer.

Wright, S.J., Trakhtenbrot, A., Bohrer, G., Detto, M., Katul, G.G., Horvitz, N., MullerLandau, H.C., Jones, F.A., Nathan, R., 2008. Understanding strategies for seed dispersal by wind under contrasting atmospheric conditions. Proc. Natl. Acad. Sci. U. S. A. $105,19084-19089$. 